\title{
Correlation of Clinical Signs and Symptoms in Ventriculoperitoneal Shunt Dysfunction in Children- A Cross Sectional Study
}

\section{Logavengatesh $\mathrm{KV}^{1}$, Santosh Mohan Rao Kanangi ${ }^{2 *}$, Radhika $\mathbf{R}^{3}$, Janani $\mathbf{S}^{4}$ and Chidambaram $\mathbf{B}^{\mathbf{5}}$}

${ }^{1}$ Paediatric Resident, Department of Paediatrics, Kanchi Kamakoti CHILDS Trust Hospital (KKCTH), Chennai, India

${ }^{2}$ Consultant Paediatric Neurosurgeon, Kanchi Kamakoti CHILDS Trust Hospital (KKCTH), Chennai, India

${ }^{3}$ Consultant Paediatric Emergency Medicine, Department of Paediatrics and

Emergency Medicine, Kanchi Kamakoti CHILDS Trust Hospital (KKCTH), Chennai, India

${ }^{4}$ Consultant Paediatrician, Department of Paediatrics, Kanchi Kamakoti CHILDS

Trust Hospital (KKCTH), Chennai, India

${ }^{5}$ Consultant Paediatric Neurosurgeon, Department of Paediatric Neurosurgery,

Kanchi Kamakoti CHILDS Trust Hospital (KKCTH), Chennai, India

*Corresponding Author: Santosh Mohan Rao Kanangi, Consultant Paediatric

Neurosurgeon, Kanchi Kamakoti CHILDS Trust Hospital (KKCTH), Chennai, India.
Received: January 26, 2021

Published: March 01, 2021

(C) All rights are reserved by Santosh Mohan

Rao Kanangi., et al.

\section{Abstract}

Aim: To study the usefulness of clinical symptoms and signs in predicting ventriculoperitoneal shunt malfunction in children.

Materials and Methods: The study was a cross sectional study of all patients with suspected ventriculoperitoneal shunt dysfunction who presented to the ER. The study was done in a single centre metropolitan tertiary care paediatric hospital over a period of one year. Data from 38 patients were obtained and was analysed using SPSS 14 and Microsoft Excel software.

Results: VP shunt block occur more commonly in males and more frequently between the ages of 1-5years. Congenital aqueductal stenosis was the most common aetiology amongst those undergoing shunt revision. Most shunt revisions occurred within 3-12months of the previous shunt surgery. Vomiting, altered sensorium and seizures were the most common presenting symptoms. Bulging AF, CSF leak from operated site and the sunset sign were definitive signs of shunt dysfunction. $74 \%$ of cases had an identifiable ventricular catheter displacement on CT scan. The most common cause was tube block by ependyma and infection as a cause for block was rare.

Conclusion: No single clinical sign was shown to be statistically significant in differentiating children who needed a shunt revision from others with similar symptoms. Neuroimaging was most useful to confirm the suspicion of a shunt dysfunction.

Keywords: Ventriculoperitoneal (VP) Shunt; Shunt Dysfunction/Malfunction; Paediatric Hydrocephalus; Shunt Revision; Vomiting; Sunset Sign; Neuroimaging

\section{Introduction}

Hydrocephalus and shunt dysfunction in paediatrics are very common problems. The biggest complication and challenge after a VP shunt surgery is shunt block which presents to the ER and necessitates in most cases a VP shunt revision. The symptoms of shunt dysfunction namely headache, vomiting, drowsiness and oc- 
ulomotor palsies are unfortunately not seen or are often recognised late in many children especially the younger ones. It was therefore thought worthwhile to study the clinical profile of patients undergoing VP shunt surgeries over a year and see if any relevant clinical sign/marker could be found.

\section{Aim}

To study the usefulness of clinical symptoms and signs in predicting ventriculoperitonal shunt dysfunction in children. The study was not intended to comment on the managment of hydrocephalus and the use of alternative methods of CSF diversion like endoscopic third ventriculostomy (ETV) etc.

\section{Materials and Methods}

This was a cross sectional study and was carried out in a single centre metropolitan tertiary care paediatric hospital over a period of one year. The paediatric hospital is a full-fledged tertiary care paediatric centre with a PICU, NICU, and has training programmes in all subspecialities of paediatrics including paediatric neurosurgery. VP shunt is a regularly performed surgical procedure in the paediatric neurosurgical department. The study was performed jointly by the paediatric and neurosurgical departments. The study was for a period of 12 months. The study was approved by the hospital ethics committee. Informed consent was obtained for all patients prior to including them in the study. It was a clinical academic study and no funding was obtained and thus there are no financial disclosures to be made.

- Inclusion Criteria: All patients between 0 to 17 years who presented with symptoms of suspected shunt dysfunction to the ER.

- Exclusion Criteria: Shunts other than VP shunts like VA shunt and also those who had undergone ETV were excluded from the study.

- Study Design: This a cross sectional study to assess the usefulness of clinical symptoms and signs that predict ventriculoperitoneal shunt malfunction.
- Data collection technique and tools: Data collection included demographic details and other parameters such as indication for ventriculoperitoneal shunt, number of prior shunt revisions as well as the time interval between the shunt procedure and development of current symptoms. Clinical features associated with shunt malfunction such as headache, vomiting, seizures, abdominal pain, bulging anterior fontanelle, sunset sign, sensorium of the patient were also recorded. Evidence of shunt leakage, inflammation or shunt exposure along the extracranial part of the shunt were noted. Loose stools was included as it served to differentiate those with shunt dysfunction and others who presented with vomiting. Radiographical findings of CT, MRI brain scans and shunt series Xrays were reviewed and documented. Patients were followed up till they were discharged from the hospital.

\section{Data analysis}

The data was analysed using SPSS 14 and Microsoft Excel software. Odds ratio for the symptoms and clinical features leading to shunt revision was calculated using SPSS 14 software.

\section{Results}

A total of 38 patients were in the study with suspected shunt dysfunction. Data analyses is given below.

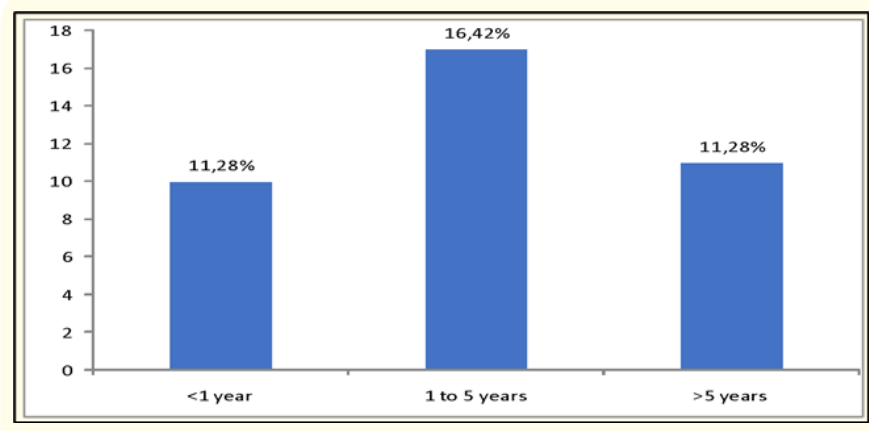

Figure 1: Age Distribution.

$16(42 \%)$ were between the age of 1 to 5 years, 11 (28\%) patients were less than one year, and $11(28 \%)$ patients were above 5 years. 


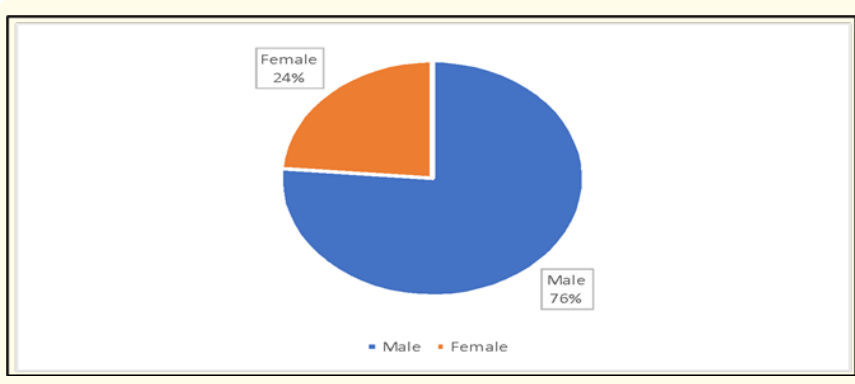

Figure 2: Gender Distribution.

Majority of our study population were boys.

$76 \%$ boys $(n=29)$ and $24 \%$ girls $(n=9)$.

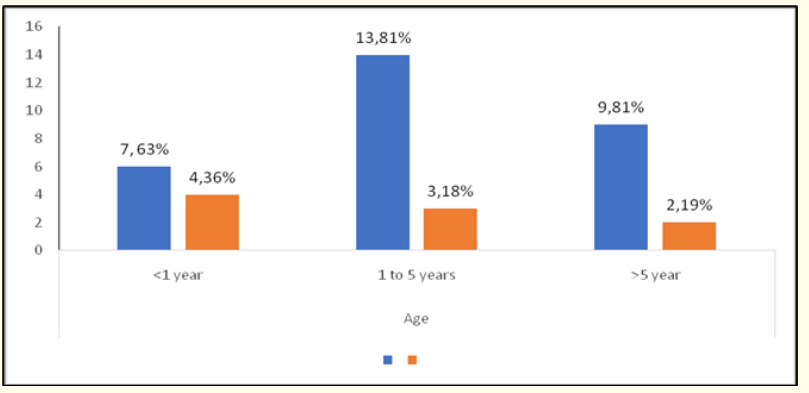

Figure 3: Gender Distribution According to Age.

There is a male preponderance in each age group.

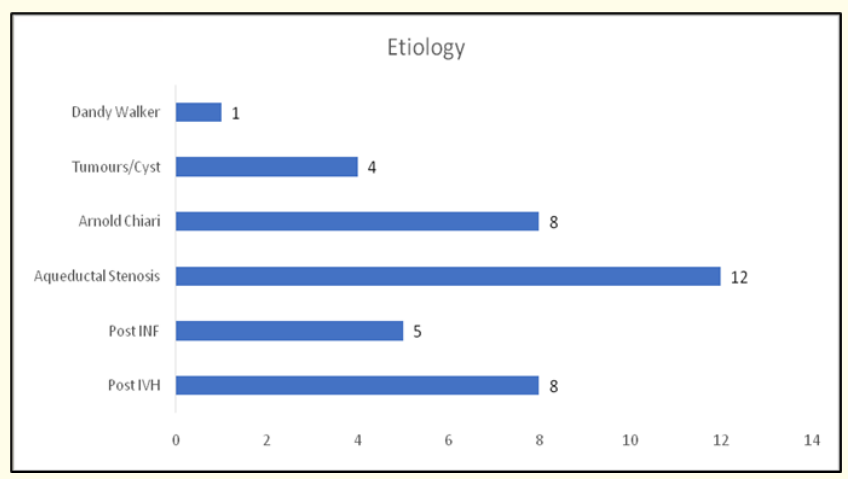

Figure 4: Indication for Ventriculoperitoneal Shunt in the study population.

(IVH - Intraventricular Haemorrhage, INF - infection).
The most common indication for VP shunt was congenital cerebral aqueductal stenosis which was seen in 12 (31\%), followed by intraventricular haemorrhage in 8 (21\%). Arnold Chiari malformation with hydrocephalus was seen in 8 (21\%), CNS infection in 5 (13\%), Tumours in $3(7.8 \%)$ and porencephalic cyst and Dandy Walker malformation was seen in one each (2.6\%).

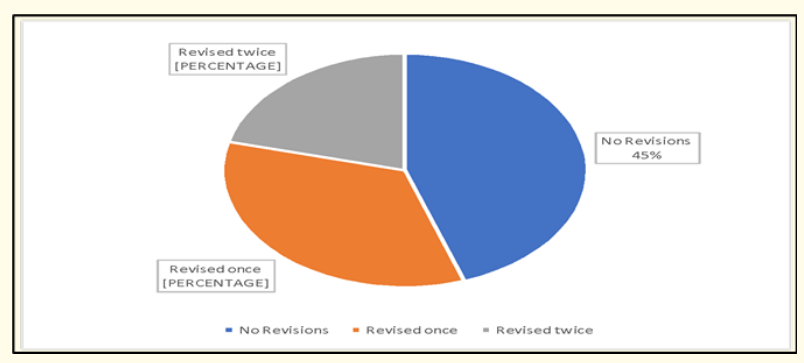

Figure 5: Number of Shunt Revisions prior to our study. $45 \%(n=17)$ of study population had no VP shunt revision prior to our study, 13 patients (34\%) underwent one shunt revision and eight patients $(21 \%)$ had two shunt revisions prior to our study.

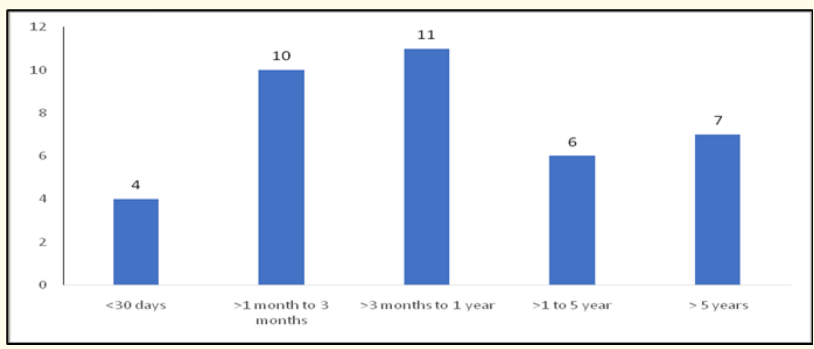

Figure 6: Duration between last shunt surgery and current symptoms:

$28 \%(n=11)$ developed symptoms between 3 months to 1 year, $10 \%(n=4)$ developed symptoms within30 days, 26\% (n=10) developed symptoms between one and three months, 15\% $(n=6)$ developed symptoms between 1 to 5 years and $18 \%(n=7)$ had symptoms after 5 years. 


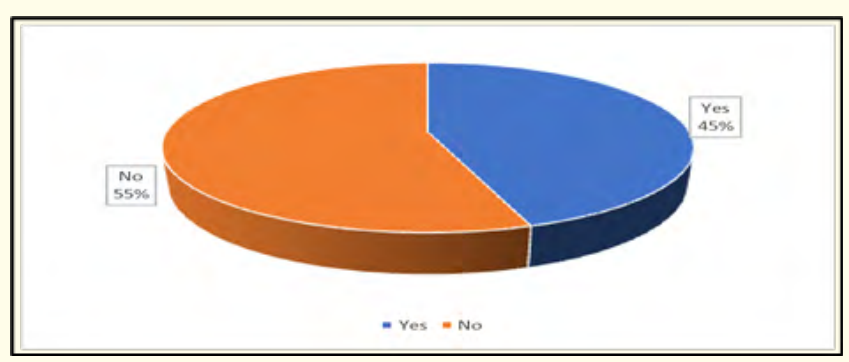

Figure 7: Vomiting at presentation.

$45 \%$ of study population $(n=17)$ had vomiting at presentation.

Analysis of clinical features:

Symptoms at presentation

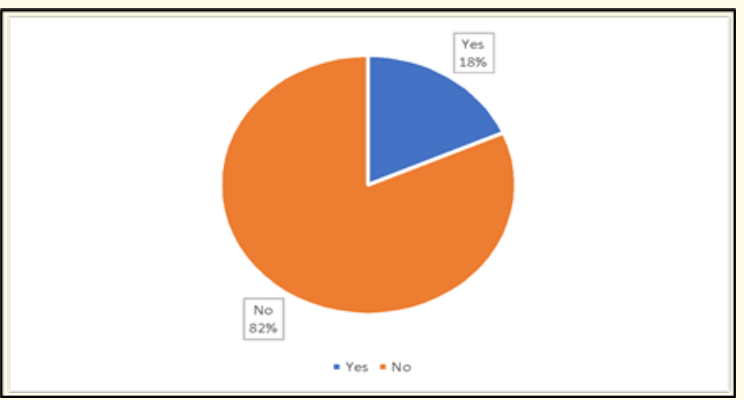

Figure 8: Headache at presentation.

$18 \%$ of study population $(n=7)$ had headache at presentation.

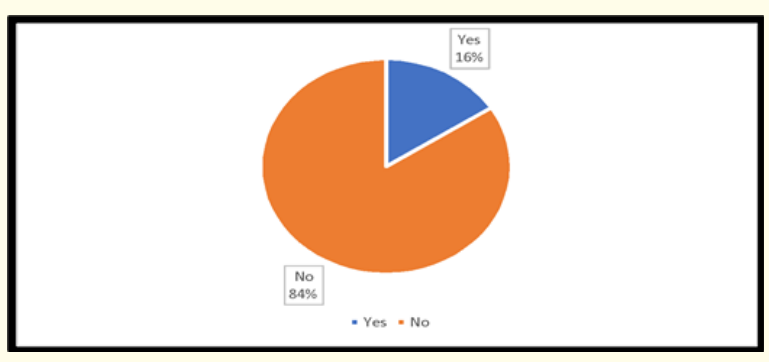

Figure 9: Fever at presentation.

$16 \%$ of study population $(n=6)$ had fever at presentation.

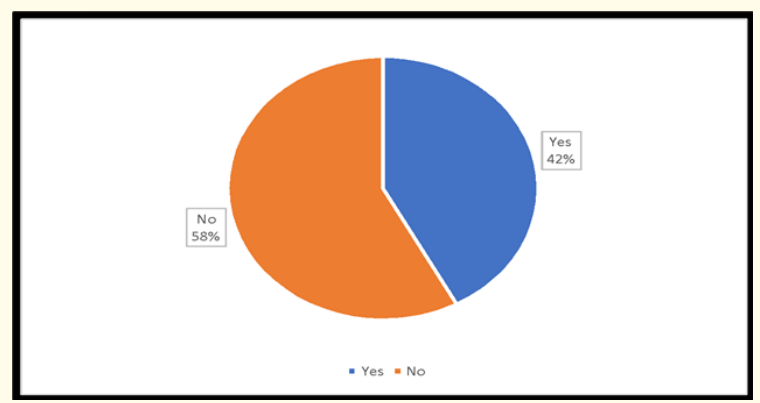

Figure 10: Seizures at presentation.

$16(42 \%)$ patients had seizures at presentation.

Other symptoms and signs

\begin{tabular}{|c|c|c|}
\hline Other Symptoms and Signs & Frequency & Percentage \\
\hline Abdominal Distension & 1 & 2.6 \\
\hline Poor Oral Intake & 2 & 5.2 \\
\hline Refusal of Feeds & 1 & 2.6 \\
\hline Loose Stools & 1 & 2.6 \\
\hline
\end{tabular}

Table 1: Other Symptoms at presentation.

\section{Neurological signs at presentation}

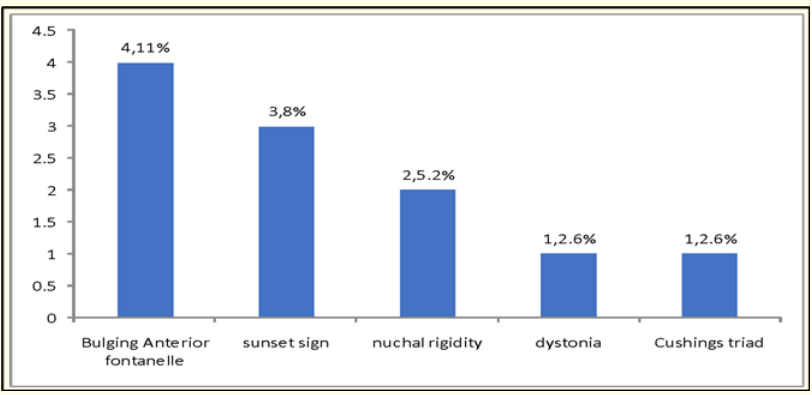

Figure 11: Neurological Signs at presentation.

Bulging AF is seen in $4(11 \%)$, Sunset sign in $3(8 \%)$, nuchal rigidity in $2(5.2 \%)$ and one each had dystonia and Cushings triad (2.6\%) (hypertension, bradycardia and irregular breathing). 


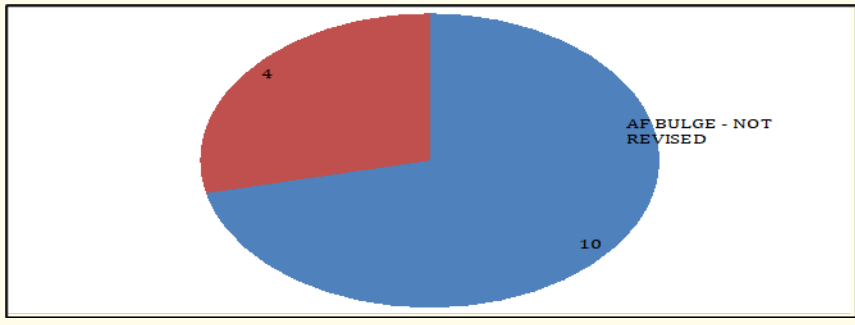

Figure 12: Bulging $\mathrm{AF}$ and shunt revision.

Anterior fontanellae was open in 14 (36\%) patients, 4 (28\%) had bulging fontanellae and all of them required shunt revision.

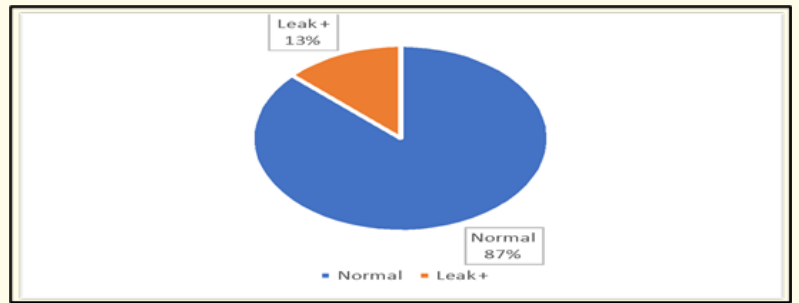

Figure 13: Shunt site leak in our study population. Shunt leak was found in five patients (13\%) the shunt site was normal in the rest

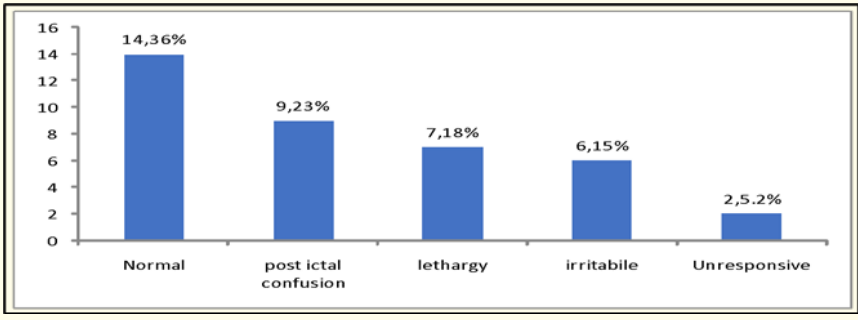

Figure 14: Sensorium at presentation.

Of the 38 patients, 24 (63\%) had altered sensorium at presentation. $9(23 \%)$ were in a post ictal state, 7 (18\%) were lethargic, 6 $(15 \%)$ were irritable and $2(5.2 \%)$ were unresponsive.
AVPU scale at presentation

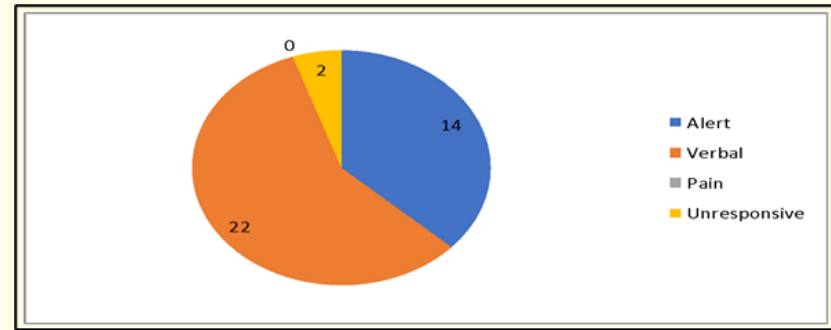

Figure 15: AVPU scale at presentation.

14 (36\%) were alert (A), 22 (63\%) were verbally responsive (V) and $2(5.2 \%)$ were unresponsive (U).

Glasgow coma scale (GCS) at presentation

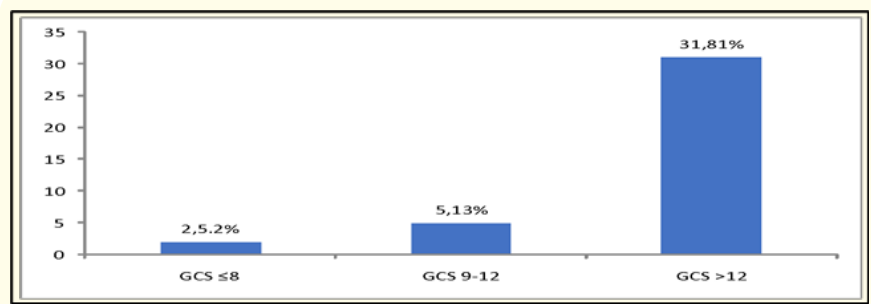

Figure 16: Glasgow coma scale at presentation.

31 patients (81\%) had GCS between 13 to 15 , five patients (13\%) had GCS between 9 to 12 and two patients (5.2\%) had very low GCS of $\leq 8$.

\section{Radiological investigations}

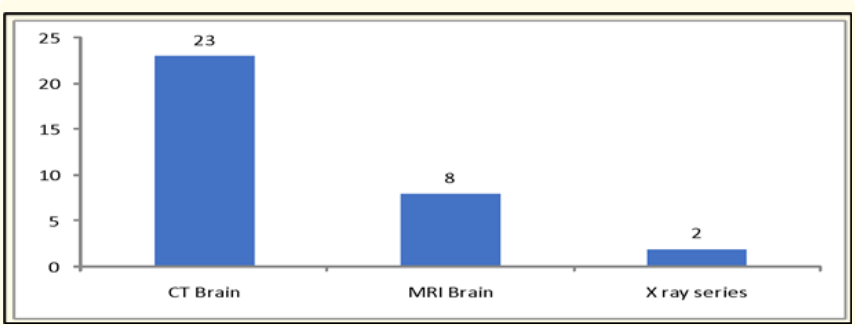

Figure 17: Radiographical Investigations. 
In this study 31 (81\%) patients underwent radiographic imaging to confirm or refute diagnosis of shunt dysfunction. $23(60 \%)$ underwent CT brain and among this 23 only $2(5 \%)$ required X rays in addition to CT imaging, 8 (21\%) underwent MRI scan.

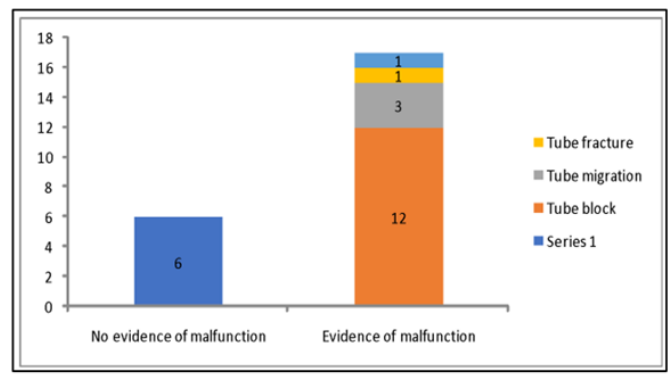

VP shunt $\mathrm{X}$-ray series

Figure 18: Findings in CT Brain.

CT Brain was done in 23 children (60\%), evidence of shunt malfunction i.e increasing hydrocephalus was found in 17 (74\%). Among the 18 children with increasing hydrocephalus 12 (70\%) had tube block,3 had (17\%) tube displacement and $1(6 \%)$ had tube fracture and in $1(6 \%)$ we could not explain the reason for increase in hydrocephalus and hence required Xray series which showed fracture of the tube at the level of the neck.

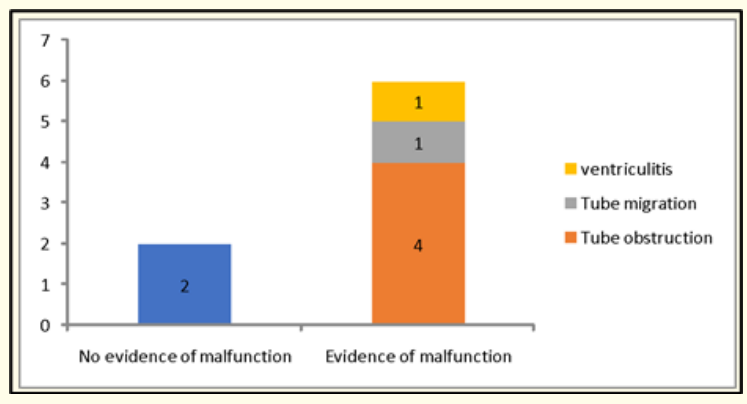

Figure 19: Findings in MRI Brain.

$8(21 \%)$ children required MRI brain. Out of the 8 children who had MRI, 6 (75\%) had evidence of increasing hydrocephalus and $2(25 \%)$ had normal MRI. Among these 6,4 (66\%) had evidence of tube block and $1(16 \%)$ had evidence of tube displacement and 1 $(16 \%)$ had evidence of ventriculitis.

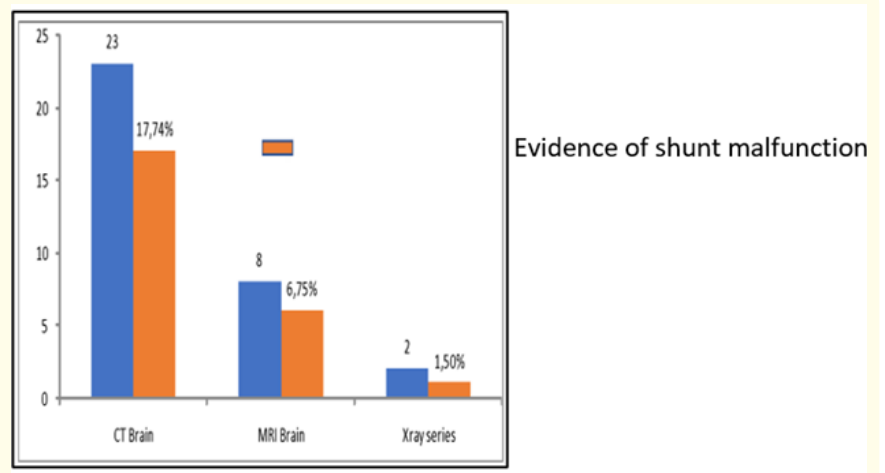

Figure 20: Radiological investigations Vs evidence of shunt malfunction.

Of the 23 children who underwent CT brain, 17 (74\%) showed evidence of shunt malfunction, among the 8 children who underwent MRI Brain 6 (75\%) had shunt malfunction, $X$ ray series was done in 2 patients, of which one child (50\%) had tube fracture.

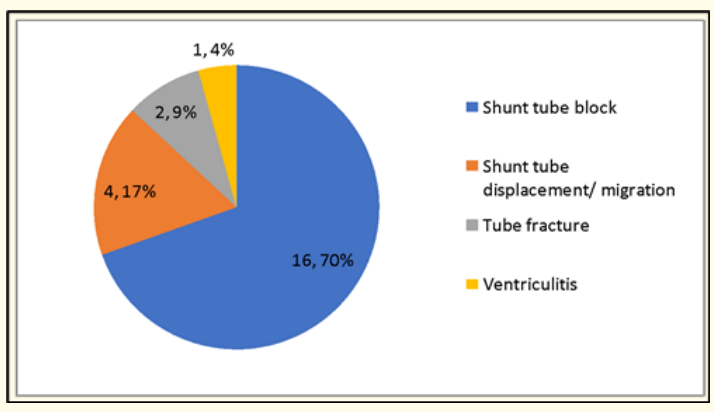

Figure 21: Reason for shunt malfunction.

Most common reason for shunt revision is tube block $(\mathrm{n}=$ $16,69 \%)$ followed by tube displacement $(n=4,17 \%)$, tube fracture $(\mathrm{n}=2,9 \%)$ and ventriculitis $(\mathrm{n}=1,4 \%)$.

\section{Shunt Revision Vs Shunt not revised}

- Children who underwent shunt revision were taken as group A

- $\quad$ Children who did not require shunt revision were taken as group B 


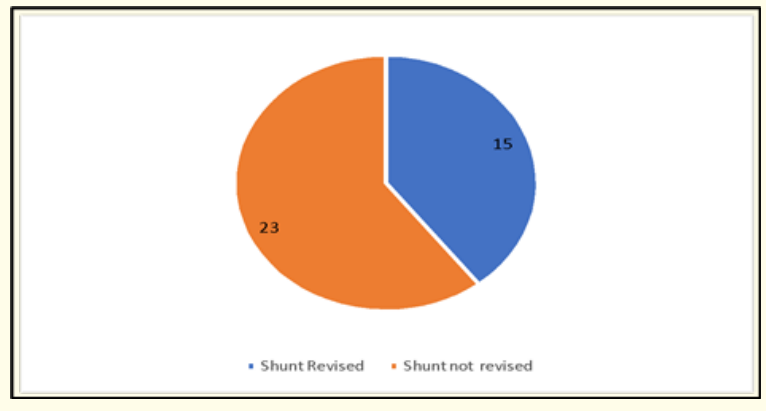

Figure 22: Shunt Revision (Group A) Vs Shunt not revised (Group B).

Of the 38 patients with suspected shunt malfunction, 23 (61\%) underwent shunt revision.

Symptoms and signs at presentation in patients who required shunt revision (Grp A)

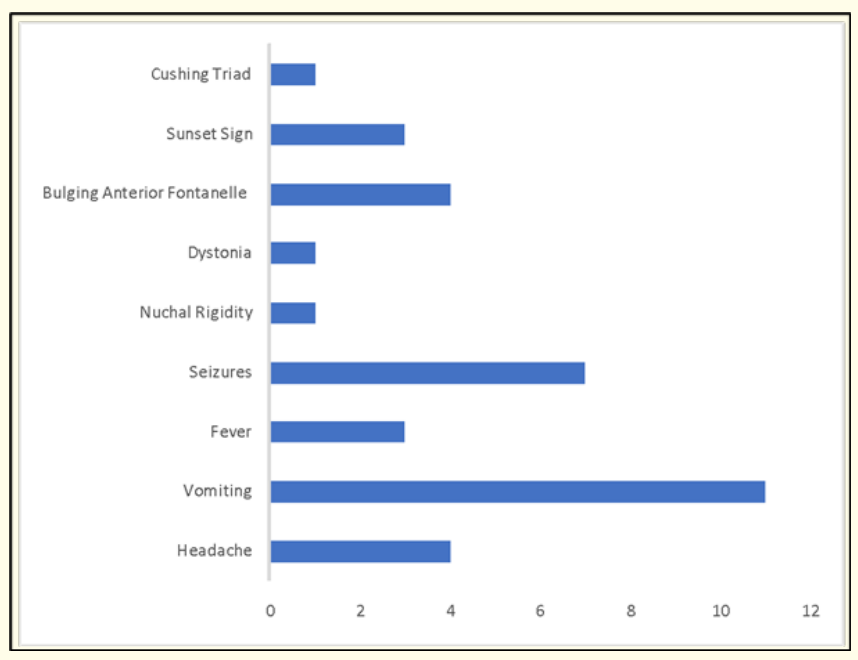

Figure 23: Symptoms and Signs in Patients with Shunt Revision.

Vomiting was the most common symptom ( $\mathrm{n}=11$ ) $48 \%$ followed by seizures $(n=7,30 \%)$, bulging anterior fontanelle $(14 \%$, $n=4)$, sunset sign $(13 \%, n=3)$ and Cushing's triad was seen in 1 patient $(3.5 \%)$ in shunt revision group.
Symptoms and signs at presentation in patients who did not require shunt revision (Group B)

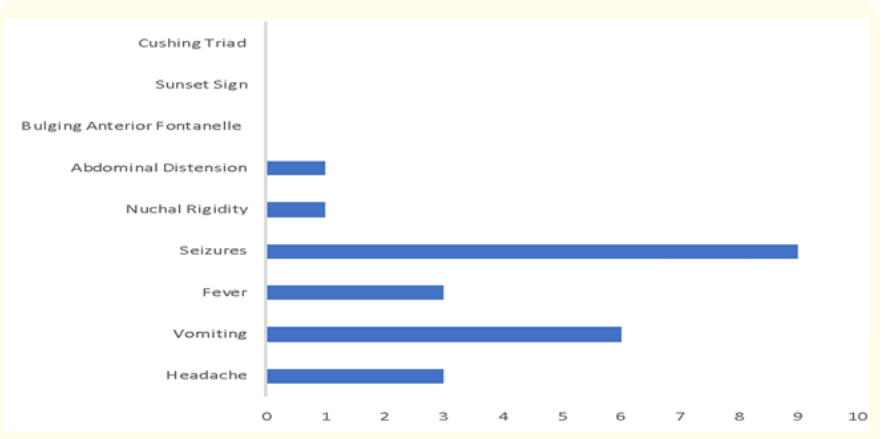

Figure 24: Symptoms and signs at presentation in patients who did not require shunt revision (Group B).

Seizure was the most common presentation $(n=9,60 \%)$ followed by vomiting $(n=6,40 \%)$, Fever $(n=3,20 \%)$ and headache ( $n=3,20 \%$ ) in children who doesn't require VP shunt. Bulging anterior fontanelle, sunset sign, dystonia and Cushing triad were not observed in any of these children.

Predictability of clinical features for shunt revision

Headache

\begin{tabular}{|c|c|c|c|c|}
\hline \multicolumn{2}{|c|}{} & \multicolumn{2}{c|}{ Headache } & Total \\
\hline \multirow{2}{*}{ Shunt } & Yes & No & \\
\hline \multirow{2}{*}{} & Nevised & 4 & 19 & 23 \\
\hline & Not Revised & 3 & 12 & 15 \\
\hline \multicolumn{2}{|c|}{ Total } & 7 & 31 & 38 \\
\hline
\end{tabular}

Table a

Four patients with shunt revised had headache, three patients presented with headache but did not undergo shunt revision. Odd's ratio for Headache towards shunt revision is 0.84 (CI 0.16 to 4.44 ).

\section{Vomiting}

11 patients who presented with vomiting underwent shunt revision. Six patients whose shunts were not revised presented with 


\begin{tabular}{|c|c|c|c|c|}
\hline \multicolumn{2}{|c|}{} & \multicolumn{2}{c|}{ Vomiting } & Total \\
\hline \multirow{2}{*}{ Shunt } & Revised & 11 & 12 & 23 \\
\hline \multirow{2}{*}{} & Not Revised & 6 & 9 & 15 \\
\hline \multicolumn{2}{|c|}{ Total } & 17 & 21 & 38 \\
\hline
\end{tabular}

Table b

the complaints of vomiting. The odd's ratio of vomiting leading to shunt revision is 1.38 (95\% CI:0.37 to 5.14 ).

Fever

\begin{tabular}{|c|c|c|c|c|}
\hline \multicolumn{2}{|c|}{} & \multicolumn{2}{c|}{ Fever } & Total \\
\hline \multicolumn{2}{|c|}{} & Yes & No & \\
\hline Shunt & Not Revised & 3 & 12 & 15 \\
\hline & Revised & 3 & 20 & 23 \\
\hline \multicolumn{2}{|c|}{ Total } & 6 & 32 & 38 \\
\hline
\end{tabular}

Table c

Six patients presented with fever, three patients' shunts were revised, and the rest three did not undergo shunt revision. The odds of fever leading to shunt revision is 0.60 (95\% CI: 0.10 to 3.46).

Bulging anterior fontanelle

Anterior fontanelle closes at 15 months, so only those patients were considered.

\begin{tabular}{|c|c|c|c|c|}
\hline \multicolumn{2}{|c|}{} & \multicolumn{2}{c|}{ Bulging AF } & Total \\
\hline \multicolumn{2}{|c|}{ Shunt } & Yes & No & \\
\hline \multirow{2}{*}{} & Not Revised & 4 & 5 & 9 \\
\hline \multicolumn{2}{|c|}{ Total } & 4 & 5 & 5 \\
\hline
\end{tabular}

Table d

All the patients with bulging anterior fontanelle had their shunts revised. The Odd's ratio for bulging anterior fontanelle patients going for shunt revision is 6.23 (95 \% CI:0.26 to 146.77).
Shunt site leak

\begin{tabular}{|c|c|c|c|c|}
\hline \multicolumn{2}{|c|}{} & \multicolumn{2}{c|}{ Leak } & Total \\
\hline \multirow{2}{*}{ Shunt } & Revised & 5 & 18 & 23 \\
\hline \multirow{2}{*}{} & Not Revised & 0 & 15 & 15 \\
\hline \multicolumn{2}{|c|}{ Total } & 5 & 33 & 38 \\
\hline
\end{tabular}

Table e

All the five patients with shunt site leak underwent shunt revision. The odds ratio for shunt site leak leading to shunt revision is 9.22 (95 \% CI:0.47 to 180.13 ).

Seizures

\begin{tabular}{|c|c|c|c|c|}
\hline \multicolumn{2}{|c|}{} & \multicolumn{2}{c|}{ Seizures } & Total \\
\hline \multicolumn{2}{|c|}{} & Yes & No & \\
\hline \multirow{2}{*}{ Shunt } & Revised & 7 & 16 & 23 \\
\hline \multirow{2}{*}{ Not Revised } & 9 & 6 & 15 \\
\hline \multicolumn{2}{|c|}{ Total } & 16 & 22 & 38 \\
\hline
\end{tabular}

Table f

Shunt revision was done in 7 patients out of 16 patients suffering from seizures. The odd's ratio for shunt revision in patients suffering from seizures is 0.29 (95\% CI:0.07 to 1.14).

Sunset sign

\begin{tabular}{|c|c|c|c|c|}
\hline \multicolumn{2}{|c|}{} & \multicolumn{2}{c|}{ Sunset Sign } & Total \\
\hline \multirow{2}{*}{ Shunt } & Yes & No & \\
\hline \multirow{2}{*}{} & Novised & 3 & 20 & 23 \\
\hline & Tot Revised & 0 & 15 & 15 \\
\hline \multicolumn{2}{|c|}{ Total } & 3 & 35 & 38 \\
\hline
\end{tabular}

Table g 
All the patients with sunset sign had their shunts revised. The odds ratio of shunt revision with sunset sign is 5.29 (95 \% CI:0.25 to 110.18$)$.

\section{Sensorium}

\begin{tabular}{|c|c|c|c|c|}
\hline \multicolumn{2}{|c|}{} & \multicolumn{2}{c|}{ Altered Sensorium } & Total \\
\hline \multicolumn{2}{|c|}{} & Yes & No & \\
\hline \multirow{2}{*}{ Shunt } & Revised & 13 & 10 & 23 \\
\hline \multirow{2}{*}{} & Not Revised & 11 & 4 & 15 \\
\hline \multicolumn{2}{|c|}{ Total } & 24 & 14 & 38 \\
\hline
\end{tabular}

Table h

The odds ratio for shunt revision with altered sensorium is $0.4795 \%$ CI:0.12 to 1.94 .

Imaging

CT and MRI brain

\begin{tabular}{|c|c|c|c|c|}
\hline \multicolumn{2}{|c|}{} & \multicolumn{2}{|c|}{$\begin{array}{c}\text { Hydrocephalus in CT } \\
\text { \& MRI }\end{array}$} & Total \\
\hline \multicolumn{2}{|c|}{} & Yes & No & \\
\hline Shunt & Revised & 22 & 1 & 23 \\
\hline \multirow{2}{*}{ Not Revised } & 2 & 6 & 8 \\
\hline \multicolumn{2}{|c|}{ Total } & 24 & 7 & 31 \\
\hline
\end{tabular}

Table i

20 patients showed hydrocephalus with dilated ventricles, out of which shunts of 18 patients were revised, two patients showed hydrocephalus in CT, but did not undergo shunt revision. The odds ratio for a positive imaging of hydrocephalus leading to shunt revision is 66.60 (95\% CI:5.08 to 857.72) ( $<<0.01)$.

\section{Discussion}

Ventriculoperitoneal shunts (VP shunts) have been one of the main modalities of treatment for hydrocephalus for more than half a century. Complications such as shunt block, shunt migration and infection during the course require shunt revision surgeries. However, not all the symptoms occurring post ventriculoperitoneal shunt are related to shunt malfunction.
A review of literature about similar studies done in the past revealed similar studies in infants done in the past by various authors [1-3]. The male preponderance of 3:1 in shunt revision patients was also observed in earlier studies [4-6]. Congenital aqueductal stenosis was reported as the most common aetiology for hydrocephalus [2,7] amounting to nearly one third of all cases. The incidence of intraventricular hemorrhage resulting in hydrocephalus ranged from $21 \%$ in our study, to $10 \%$ [8] or even less in other studies [2]. IVH was the least common of all etiologies for hydrocephalus in an other study [4].

Hydrocephalus associated with Arnold Chiari malformation or the development of hydrocephalus subsequent to surgery for Arnold Chiari malformation accounted for $21 \%$ of the cases. This was unique as literature about hydrocephalus associated with Chiari malformations is sparse [9].

One patient in our study had Dandy Walker malformation as a cause for hydrocephalus. This is rare and the incidence of hydrocephalus in Dandy walker syndrome varies from 20 to 80\% [10]. Post-meningitic hydrocephalus accounted for $13 \%$ in our study of which two were tuberculous meningitis. Tuberculous meningitis was the most common infective cause for hydrocephalus $[2,4,11]$ and some studies state that $85 \%$ of children with TB meningitis develop hydrocephalus [12].

Tumours, especially posterior fossa tumours, which are very common in children and space occupying lesions are another important group causing hydrocephalus. Studies have shown [13] that 10 to $40 \%$ of children have persistent hydrocephalus despite successful surgical excision of the lesion. In our study, 7.8\% ( $n=3)$ had hydrocephalus due to tumours and $2.6 \%(n=1)$ had porencephalic cyst.

25 out of 38 patients developed symptoms within a year of having the first shunt surgery, six patients developed symptoms within five years and seven patients developed symptoms after 5 years. The high rate of shunt revision in the first year after surgery was also seen in other studies $[14,15]$. One study had a shunt revision rate of $34.9 \%(n=51 / 146)[14]$.

In our study, $55 \%$ had one or more shunt revisions prior to the study whereas $45 \%$ of study population never had VP shunt revi- 
sion prior to our study, 13 (34\%) patients underwent one shunt revision and eight patients (21\%) had 2 shunt revisions prior to our study. In one study [16], 84.5\% of patients needed atleast one shunt revision surgery whilst $4.7 \%$ of patients needed more than 10 revision surgeries over a span of 15 years. Revisions were common if the first procedure is performed in babies less than 40 weeks of gestation [17].

\section{Clinical features at presentation}

The most common symptom in our study population was vomiting $45 \%(n=17)$ followed by seizures $42 \%(n=16)$, lethargy (18\%), headache (18\%), fever (16\%) and irritability (15\%). Similar incidence of presenting symptoms were seen in other paediatric studies $[2,4]$. Drowsiness was the single most important predictive factor in a study [18]. This however was not a statistically significant predictor in our study. An increase in seizures in patients who underwent ventriculoperitoneal shunts probably due to the foreign body reaction to the shunt tube material, the number of shunt revisions, infections and the location of burrhole has also been reported [19].

Headache was one of the most common symptoms associated with hydrocephalus in various studies [18,20]. The incidence of both migrainous and non-migrainous headache was reported to be increased in patients with VP shunt for hydrocephalus [21].

Fever was a presenting complaint in $16 \%$ of the patients in the present study. Fever was found to be the predictor for shunt infection in a previous study [22]. Data regarding the GCS or AVPU scale in children with suspected VP shunt malfunction, at presentation is poor.

Bulging anterior fontanelle was seen in $28 \%(n=4)$ of children aged less than 18 months in the present study and all these patients underwent shunt revisions. A bulging anterior fontanelle was strongly associated with shunt blockade and is an excellent measure of raised intracranial pressure [22]. Sunset sign refers to the upward gaze palsy in patients with hydrocephalus. In the present study sunset sign was seen in $7.8 \%$ patients as compared to $13 \%$ in other studies [23]. Extracranial shunt site leak was found in five patients (13\%) in our study whereas it was $28 \%$ in another study [24].

Though all children with bulging anterior fontanelle, sun set sign and extra cranial shunt site leakage required surgical shunt revision they did not have statistical significance.

\section{Investigations}

(81\%) 31 patients required radiographical investigations to rule out shunt malfunction whereas 7 (19\%) children did not require radiological investigations. In all children who presented with suspected shunt malfunction CT was chosen as the first line investigation as it was available within our hospital and requires less sedation and is a recommended imaging modality in an emergency. MRI brain was reserved for children who were stable and in those where infection was suspected. Xray VP shunt series was performed for a selective group which was decided by the neurosurgeon after reviewing CT films and not as a routine.

In our study, CT brain was done in $60 \%(\mathrm{n}=23)$ of children, $21 \%(n=8)$ required MRI Brain, and X - ray VP shunt series (Neck, Thorax and abdomen) were taken in 2 patients. CT and MRI data can be used to predict the changes in morphology due to shunt malfunction [25]. MRI has the advantage of not being a radiation hazard to children [26].

Patients in our study population were categorised into group A (those who underwent shunt revision) and group B (those who did not undergo shunt revision) to aid statistical comparison and analyses.

- Group A: Out of 23 patients who underwent shunt revision, vomiting was the most common symptom ( $\mathrm{n}=11,48 \%$ ), seizures $(n=7,30 \%)$. Clinical signs of hydrocephalus, such as sunset sign and bulging anterior fontanelle were seen in three $(13 \%)$ and four patients (14\%) respectively. Cushing's triad was seen in 1 patient $(3.5 \%)$.

- Group B: Of the 15 patients who did not require shunt revision, seizures was the most common presentation $(\mathrm{n}=9$, $60 \%)$, vomiting ( $n=6,40 \%)$, fever $(n=3,20 \%)$ and headache ( $\mathrm{n}=3,20 \%)$. Bulging $A F$, sunset sign, dystonia and Cushing's triad were not observed in any of these children. 
Odds ratio or definitive factor analysis

There was no statistical significant difference between the 2 groups in the symptoms such as fever, vomiting, alteredsensorium, headache, seizures or signs such as sun set sign, AVPU and GCS scale. Though all children with bulging anterior fontanelle, sun set sign and extra cranial shunt site leakage required surgical shunt revision these parameters did not have statistical significance. Neuroimaging was found to be most useful for diagnosis of shunt dysfunction.

\section{Limitations of the study}

We could not follow up the cases and analyse the long term consequences of VP shunt on child development. The sample size in our study is small and hence the results obtained cannot be completely validated. Also, as this is a single centre study conducted in the Paediatric department of a tertiary care hospital the results cannot be completely generalised.

\section{Conclusion}

There was no statistically significant difference in the symptoms or signs between those children who had evidence of shunt block (requiring VP shunt revision) and those who did not require VP shunt revision but presented with similar complaints. Neuroimaging was found to be most useful for confirming shunt dysfunction.

\section{Bibliography}

1. Pal SS and Dubey S. "A study of VP shunt in management of hydrocephalus". International Surgery Journal 224.5 (2017): 1697-701.

2. Ahmed A., et al. "Outcome analysis of shunt surgery in hydrocephalus". Journal of Indian Association of Pediatric Surgeons 14.3 (2009): 98.

3. TT Lee., et al. "Unique clinical presentation of pediatric shunt malfunction”. Paediatric Neurosurgery 30.3 (1999): 122-126.

4. Pan P. "Outcome analysis of ventriculoperitoneal shunt surgery in pediatric hydrocephalus". Journal of Pediatric Neurosciences 13.2 (2018): 176.
5. Jaiswal A and Jaiswal J. "Incidence of hydrocephalus in pediatric age in a tertiary care centre of Chhattisgarh". Journal of Evolution of Medical and Dental Sciences-JEMDS (2015): 14564-71.

6. Yusuf AS., et al. "Management and outcome of infantile hydrocephalus in a tertiary health institution in Nigeria". Journal of Neurosciences in Rural Practice 8.2 (2017): 249.

7. Kumar R., et al. "Shunt revision in hydrocephalus". The Indian Journal of Pediatrics 72.10 (2005): 843-847.

8. Afsharkhas L., et al. "Intraventricular hemorrhage in term neonates: sources, severity and outcome". Iranian Journal of Child Neurology 9.3 (2015): 34.

9. Decq P., et al. "Chiari I malformation: a rare cause of non-communicating hydrocephalus treated by third ventriculostomy". JNS 95.5 (2001): 783-790.

10. Dandy Walker Malformation - NORD (National Organization for Rare Disorders) [Internet]. NORD (National Organization for Rare Disorders). (2018).

11. Huo L., et al. "Clinical Features of and Risk Factors for Hydrocephalus in Childhood Bacterial Meningitis". Journal of Child Neurology 34.1 (2019): 11-16.

12. Rajshekhar V. "Management of hydrocephalus in patients with tuberculous meningitis". Neurology India 57.4 (2009): 368.

13. Meenakshisundaram $\mathrm{N}$ and Dhandapani B. "Posterior cranial fossa space occupying lesions: an Institutional experience". International Journal of Research in Medical Sciences 6.7 (2018).

14. Park MK., et al. "A retrospective analysis of ventriculoperitoneal shunt revision cases of a single institute". Journal of Korean Neurosurgical Society 57.5 (2015): 359.

15. Agarwal N., et al. "Pediatric ventriculoperitoneal shunts and their complications: An Analysis". Journal of Indian Association of Pediatric Surgeons 22.3 (2017): 155.

16. Stone JJ., et al. "Revision rate of pediatric ventriculoperitoneal shunts after 15 years”. JNS: Pediatrics 11.1 (2013): 15-19. 
17. Patwardhan RV and Nanda A. "Implanted ventricular shunts in the United States: the billion-dollar-a-year cost of hydrocephalus treatment". Neurosurgery 56.1 (2005): 139-145.

18. Barnes NP., et al. "Ventriculoperitoneal shunt block: what are the best predictive clinical indicators?". Archives of Disease in Childhood 87.3 (2002): 198-201.

19. Sato O., et al. "Hydrocephalus and epilepsy". Child's Nervous System 17 (2001): 76-86.

20. Rekate HL and Kranz D. "Headaches in patients with shunts". In Seminars in pediatric neurology 16.1 (2009): 27-30.

21. Stellman-Ward GR., et al. "The incidence of chronic headache in children with shunted hydrocephalus". European Journal of Pediatric Surgery 7 (1997): 12-14.

22. Piatt JH and Garton HJ. "Clinical diagnosis of Ventriculoperitoneal shunt failure among children with hydrocephalus". Pediatric emergency care 24.4 (2008): 201-10.

23. Boragina M and Cohen E. "An infant with the "setting-sun" eye phenomenon". Canadian Medical Association Journal 175.8 (2006): 878.

24. Ghritlaharey RK., et al. "Ventriculoperitoneal shunt complications needing shunt revision in children: a review of 5 years of experience with 48 revisions". African Journal of Paediatric Surgery 9.1 (2012).

25. Sellin J., et al. "Utility of computed tomography or magnetic resonance imaging evaluation of ventricular morphology in suspected cerebrospinal fluid shunt malfunction". JNS: Pediatrics (2014): 1-7.

26. Torrey SB., et al. "Benefits of brain magnetic resonance imaging over computed tomography in children requiring emergency evaluation of ventriculoperitoneal shunt malfunction: reducing lifetime attributable risk of cancer". Pediatric Emergency Care 31.4 (2015): 239-242.

\section{Assets from publication with us}

- Prompt Acknowledgement after receiving the article

- Thorough Double blinded peer review

- Rapid Publication

- Issue of Publication Certificate

- High visibility of your Published work

Website: www.actascientific.com/

Submit Article: www.actascientific.com/submission.php

Email us: editor@actascientific.com

Contact us: +919182824667 